\title{
Technology Road Mapping for Innovation Pathways of Fibrates: A Cross-Database Patent Review
}

\author{
Xiao-Wen Yu, Hao Hu*, Xiu-Ping Chen, Yuanjia Hu and Yi-Tao Wang \\ State Key Laboratory of Quality Research in Chinese Medicine, Institute of Chinese Medical Sciences, University of Macau, \\ Macao \\ *For correspondence: Email: haohu@umac.mo; Tel: 00853-88228538; Fax: 00853-28841358
}

\begin{abstract}
Purpose: To examine international technology development of fibrates based on a cross-database quantitative patent review and to describe the evolution pathway for fibrates by means of a technology roadmap.

Methods: The patent data were collected in March 2013 from United States Patent and Trademark Office (USPTO), European Patent Office (EPO) and China Intellectual Property Right Net (CNIPR) to broadly represent global patent activities.

Results: This study selected and examined 84 patents from USPTO, 41 patents from EPO and 39 patents from CNIPR. It showed that most of the fibrate patents were fenofibrate patents $(41.67 \%$ at USPTO, $46.34 \%$ at EPO and $33.33 \%$ at CNIPR). The number of preparation patents (44 at USPTO, 24 at EPO and 17 at CNIPR) and combination patents (23 at USPTO, 11 at EPO and 15 at CNIPR) was obviously larger than other types of fibrate patents. The technology roadmap shows that new monomersor derivatives of fibrates can drive fibrate evolution into a new cycle of application-synthesiscombination-preparation.

Conclusion: This study provides a comprehensive picture of fibrate development. It will aid researchers, entrepreneurs, investors and policymakers to identify foci for fibrate research and ensure better decision-making.
\end{abstract}

Keywords: Cross-database, Evolution pathway, Fibrates, Patent review, Technology roadmap

\begin{abstract}
Tropical Journal of Pharmaceutical Research is indexed by Science Citation Index (SciSearch), Scopus, International Pharmaceutical Abstract, Chemical Abstracts, Embase, Index Copernicus, EBSCO, African Index Medicus, JournalSeek, Journal Citation Reports/Science Edition, Directory of Open Access Journals (DOAJ), African Journal Online, Bioline International, Open-J-Gate and Pharmacy Abstracts
\end{abstract}

\section{INTRODUCTION}

Hypertriglyceridemia (HTG) is a major risk factor in many cardiovascular and cerebrovascular diseases, including coronary heart disease, stroke, atherosclerosis [1,2]. More and more research has revealed elevated triglyceride (TG) to be an independent risk factor for cardiovascular disease [3,4]. In China, the morbidity of HTG among people aged over 18 years is $11.9 \%$, morbidity is increasing year by year and HTG is increasingly affecting younger and younger people [5].
As the drug of first choice for reducing TG clinically, fibrates play important roles in metabolic regulation. However, more than $90 \%$ of the market share in China belongs to foreign companies. About 10 local firms can only share the rest $10 \%$ of the market. To become major players in fibrate industry, local pharmaceutical companies in China should significantly boost their research and development (R\&D) efforts in fibrate technology. It is therefore critical for researchers and manufacturers to be aware of publications and patents in this field across 
different laboratories, companies and countries to map the development of fibrates and of core and new fibrate technologies.

Several studies have identified technology evolution through patent review [6-9]. Patents are often considered to be better source for the timely recognition of technological change than scientific and technical literatures [10]. Furthermore, a technology roadmap is more intuitive than traditional patent citation analysis or co-operation analysis. The use of a technology roadmap therefore makes it easier for researchers or investors to catch the latest developments in research.

The patent literature on synthetic ligands for peroxisome proliferator-activated receptor (PPAR, target of fibrates) has been reviewed qualitatively by many researchers [11-13], whereas there is no literature on the evolution and status of international fibrate technology.

This study aims to examine the international technology development of fibrates based on a cross-database quantitative patent review and to describe the evolution pathway for fibrates by means of a technology roadmap.

\section{EXPERIMENTAL}

\section{Selection of databases}

Many researchers have applied patent analysis at the national level to show the evolution of, and latest trends in, technology $[14,15]$. However, patent analysis at the national level cannot provide a comprehensive overview of global technological development.

To map the evolution of international research into fibrates, we chose the United States Patent and Trademark Office (USPTO) and the European Patent Office (EPO) to represent patent activities in developed countries and the China Intellectual Property Right Net (CNIPR) to represent patent activities in developing countries.

\section{Retrieval criteria}

Since not all patent applications receive authorisation, we believe that authorised patents are more representative than patent applications for the assessment of technology development. To optimise and maximise the results acquired from the three patent offices, we chose the same retrieval criteria 'title or abstract' at each patent office and used the names and synonyms of different fibrates as keywords. The data were collected in March 2013. It was anticipated that a proportion of the latest patents would not yet be available because of the lengthy patent application process (according to the collected data, it took on average between three and five years for the patent offices to authorise fibrate patents).

\section{Data analysis}

After the data collection, we analysed fibrate distribution at USPTO, EPO and CNIPR respectively by chemical name, year, nation, assignee, technological type and International Patent Classification (IPC) code. A technology roadmap aiming to identify the evolution of the technology based on all of the patents collected from the above patent offices was drawn up afterwards.

\section{RESULTS}

After the systematic retrieval, we identified 84 patents from USPTO, 41 patents from EPO and 39 patents from CNIPR. Table 1 showed that most of the fibrate patents were fenofibrate patents $(41.67 \%$ at USPTO, $46.34 \%$ at EPO and $33.33 \%$ at CNIPR), and that patents for fibrates were ranked second $(22.62 \%$ at USPTO, $19.27 \%$ at EPO and $30.77 \%$ at CNIPR). Gemfibrozil patents were ranked third at USPTO and EPO with percentages of 17.86 and $9.76 \%$, respectively. At CNIPR, bezafibrate, at $12.82 \%$, was ranked third, followed by gemfibrozil $(10.26 \%)$.

Figure 1 clearly shows that fibrates first emerged in the United States (US), and developed rapidly between 1985 and 2004 in both Europe and the US. During the 2000-2004 period, 31 patents received final authorisation in the US and 16 patents received final authorisation in Europe. However, after 2004 the number clearly decreased.

Fibrates in China developed in a different way. As a developing country, the Chinese fibrate industry emerged in the late 1990s and boomed in the 2000s. More and more patents have received authorisation in every five-year period from 1995, with a maximum of 19 successful applications between 2005 and 2010 . 
Table 1: Results of patent collection in different patent offices

\begin{tabular}{lccc}
\hline \multirow{2}{*}{ Chemical name } & \multicolumn{1}{c}{ N (\%) } & CNIPR \\
\cline { 2 - 4 } & USPTO & EPO & $4(10.26)$ \\
\hline Gemfibrozil & $15(17.86)$ & $4(9.76)$ & $12(30.77)$ \\
Fibrates* & $19(22.62)$ & $12(19.27)$ & $13(33.33)$ \\
Fenofibrate & $35(41.67)$ & $19(46.34)$ & $5(12.82)$ \\
Bezafibrate & $2(2.38)$ & $2(4.88)$ & -- \\
Ciprofibrate & $3(3.57)$ & - & $1(2.56)$ \\
Etofibrate & $1(1.19)$ & $3(7.32)$ & $1(2.56)$ \\
Clofibrate & $7(8.33)$ & $1(2.44)$ & -- \\
Etofylline clofibrate & $1(1.19)$ & -- & $2(5.13)$ \\
Fenofibrate acid choline salt & $1(1.19)$ & -- & $1(2.56)$ \\
Fibrate carboxylate & -- & -- & $\mathbf{3 9}$ \\
Total & $\mathbf{8 4}$ & $\mathbf{4 1}$ & \\
\hline
\end{tabular}

Note: *Fibrates refers to patents suitable for at least four different kinds of fibrate

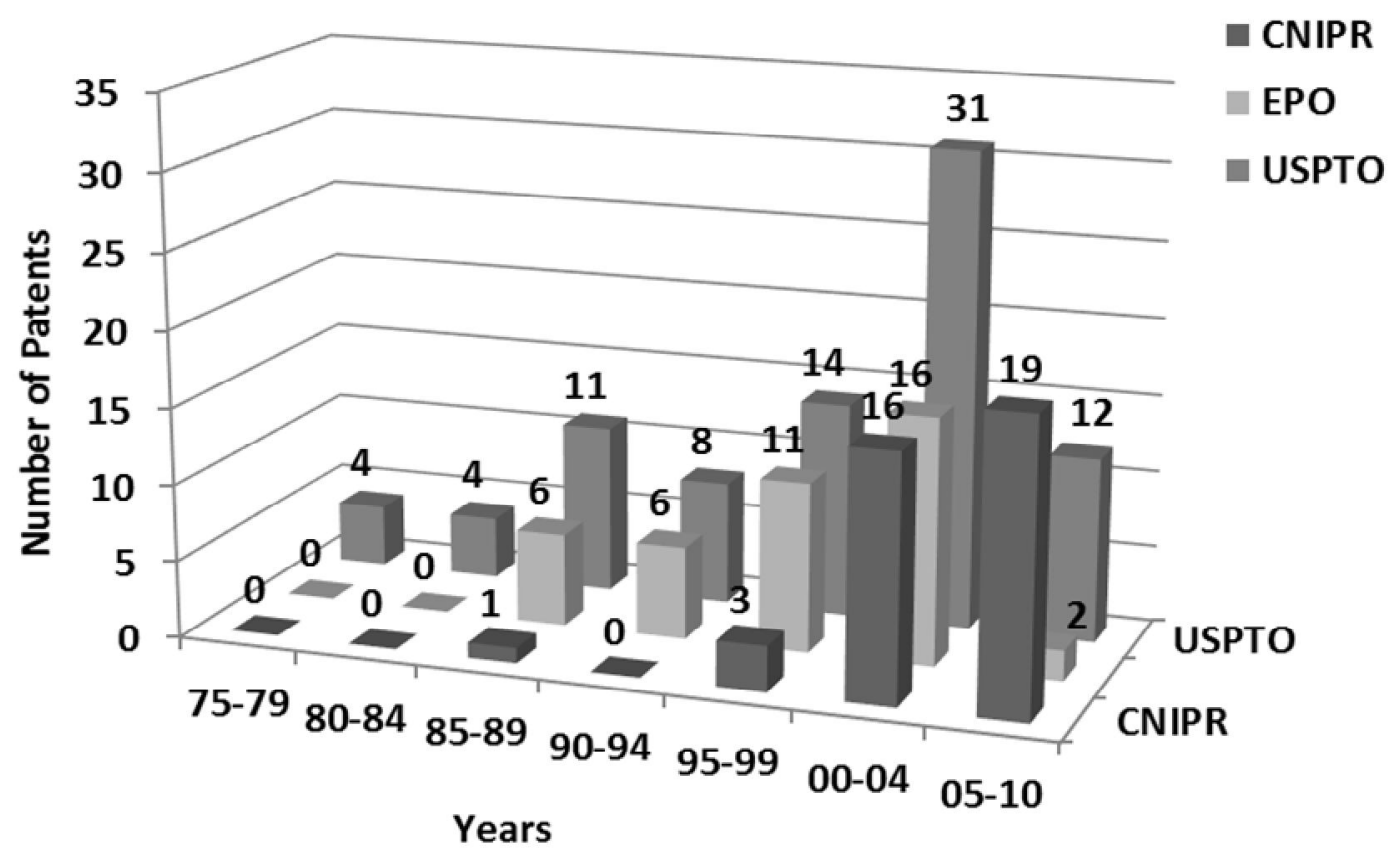

Figure 1: Number of authorised fibrate patents at USPTO, EPO and CNIPR by year of application

\section{Distribution analysis by nation}

Figure 2 reveals that in each market, the largest number of patents, which protect their assignees' rights and interests, originate within the home market. European Union applicants had 30 authorised patents in the US market and 10 in the Chinese market. US applicants received 18 authorised patents in the EU market and 5 in the Chinese market. As at the date of our data retrieval, Chinese applicants had not received any patent authorisations for the US market or the Euro-market.

Furthermore, Figure 3 shows that the fibrate patent flow from the European Union to the US was higher than that from the US to the European Union. Both the European Union and the US have fibrate patent flows to China, but China had no flow in the opposite direction.

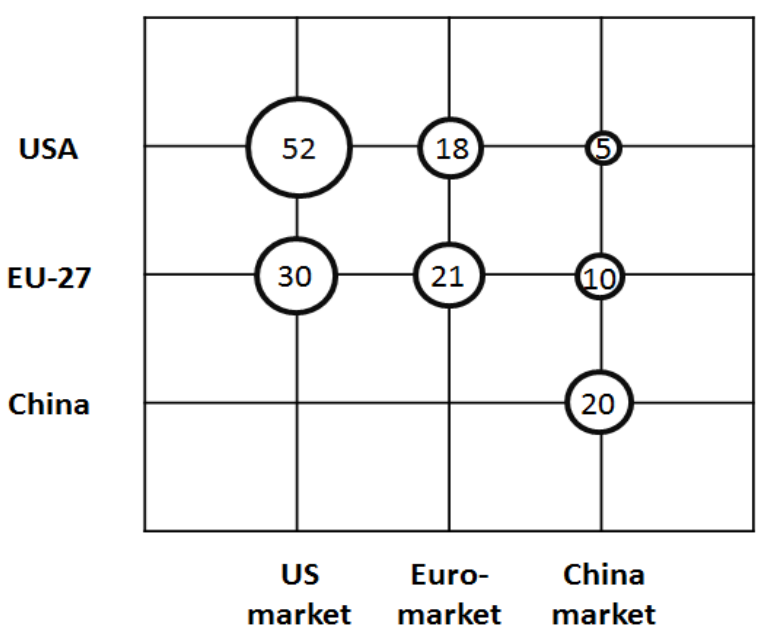

Figure 2: Distribution of patents in different market

Trop J Pharm Res, August 2015; 14(8): 1461 


\section{Distribution analysis by assignees}

Local companies in America and Europe were responsible for most of the patent applications (Figure 4). Foreign companies were the second most important actors in applications for fibrate patents, whereas very few institutes, universities or individuals applied for fibrate patents at USPTO and EPO.

Table 2 reveals the main assignees of fibrate patents in the US, Europe and China. The Table shows that four companies received protection at all three offices: US-based Abbott and Pfizer, France's Ethypharm and SkyePharma from the United Kingdom. Abbott owns the greatest number of patents, with an average patent age of 11 to 15 years.

\section{Distribution analysis by technological types}
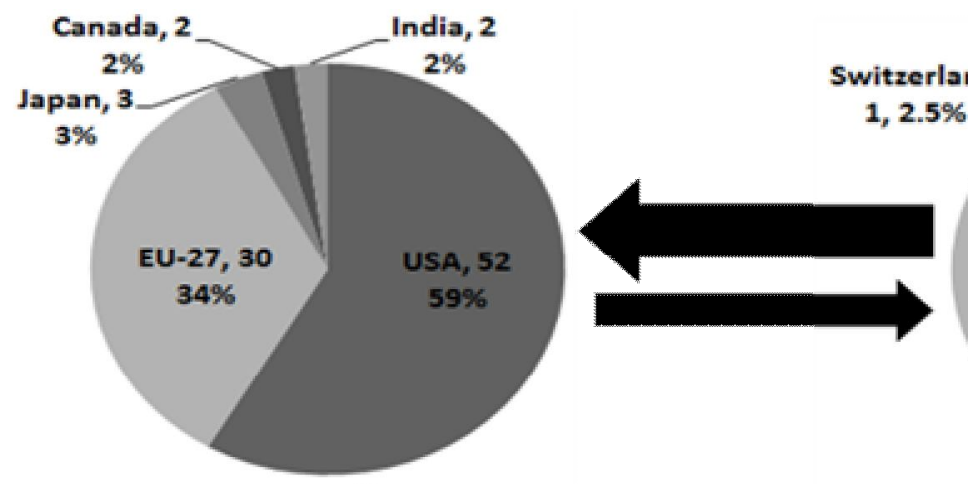

To locate key technologies, we categorised the patents into five technological types: application, synthesis, purification, combination and preparation (Table 3). From Table 3, we can easily adduce that the number of preparation patents and combination patents is obviously larger than other types of fibrate patents. Furthermore, two core types of fibrate patent (preparation of fenofibrate and combination of fibrates) are shown in Table 3.

\section{Technology roadmap for fibrates}

After analysing the distribution of technological type, we explored the innovation pathway of fibrate technology. In this part, technology road mapping is used to describe the technology trends and foci.

USPTO, 89 patents

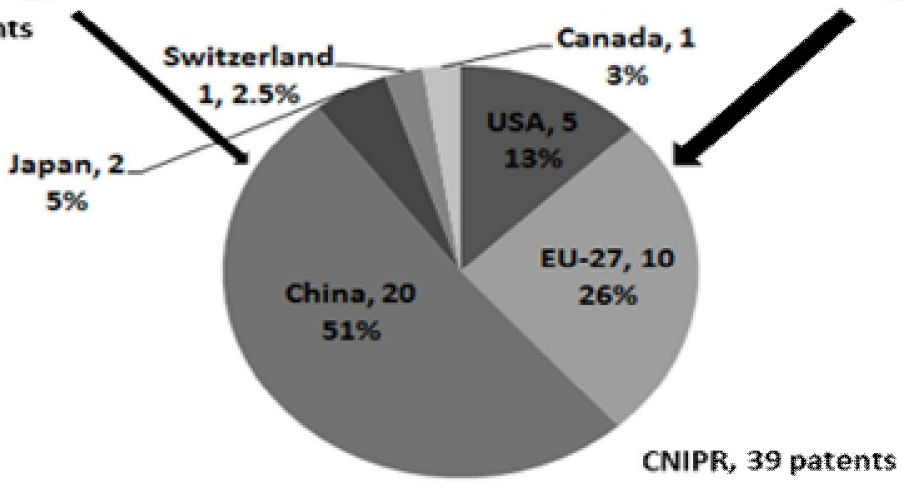

Figure 3: Fibrate patent flows between the US, Europe and China

\section{DISCUSSION}

From result presented above we can notice that, clofibrate was the first member of the fibrate class revealed to have an effect on regulating metabolism, but clofibrate also, inconveniently, was a potential safety hazard. Thus many new fibrates such as bezafibrate, gemfibrozil and fenofibrate, were synthesised by researchers based on the structure of clofibrate. However, strong variations existed between the different fibrates. Fenofibrate appeared to be more effective compared with bezafibrate, gemfibrozil and ciprofibrate [16]. As new fibrates proved to be more effective in reducing triglyceride with little adverse drug reaction, the basic technology for their preparation and combination developed rapidly. Many clinical trials with less satisfactory results followed, which showed no benefit resulted from adding fibrates to statin treatments [17]. These trials led to a reduction in enthusiasm for studies on new fibrates and their applications 


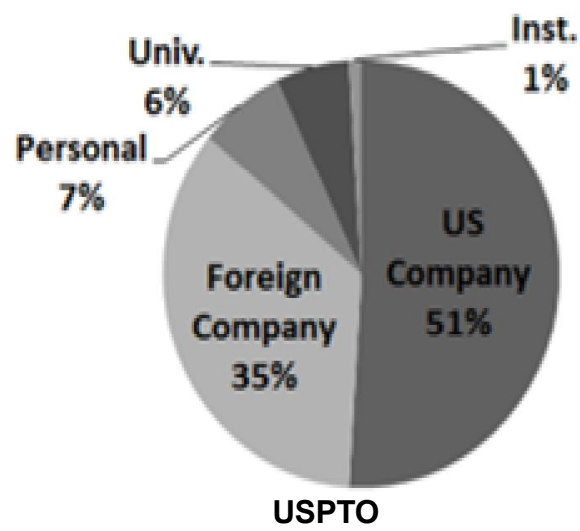

Inst. Personal.

$1 \% 3 \%$
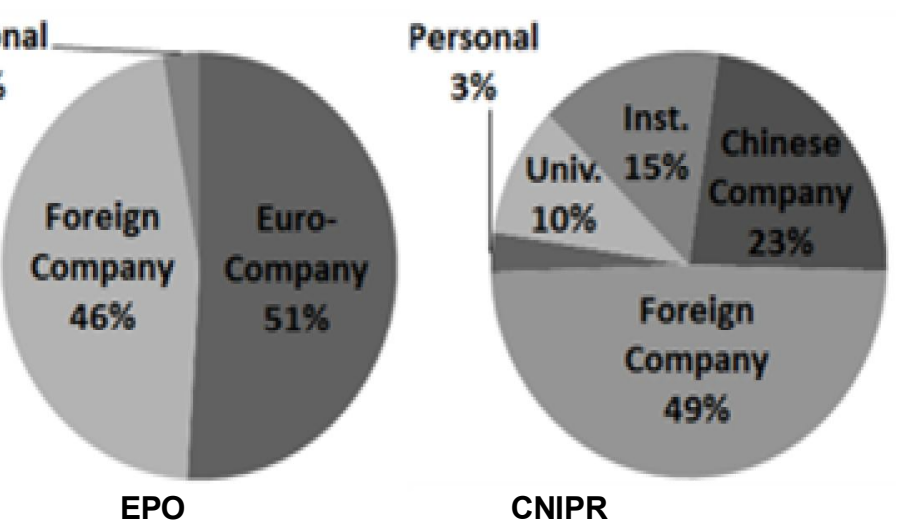

CNIPR

Figure 4: Distribution of different types of assignee at USPTO, EPO and CNIPR

Table 2: Analysis of the main assignees in different patent offices

\begin{tabular}{|c|c|c|c|c|c|}
\hline \multirow{2}{*}{ Assignee } & \multicolumn{3}{|c|}{ No. of patents/Mean age } & \multirow{2}{*}{ Attribution } & \multirow{2}{*}{ Country } \\
\hline & USPTO & $E P O$ & CNIPR & & \\
\hline Abbott Laboratories & 19/12.0 & $10 / 15.0$ & $6 / 11.0$ & $\mathrm{~F}$ & USA \\
\hline Pfizer Inc. & $11 / 19.4$ & $6 / 20.3$ & $1 / 27.0$ & $\mathrm{~F}$ & USA \\
\hline Ethypharm Ltd & $3 / 14.0$ & $4 / 15.3$ & $3 / 11.7$ & $\mathrm{~F}$ & FRA \\
\hline SkyePharma PLC & $3 / 11.7$ & $4 / 11.8$ & $1 / 12.0$ & $\mathrm{~F}$ & GBR \\
\hline Arena Pharmaceuticals Inc & $2 / 7.5$ & $0 /-$ & $1 / 9.0$ & $\mathrm{~F}$ & USA \\
\hline Veloxis Pharmaceuticals AVS & $2 / 9.0$ & $0 /-$ & $1 / 9.0$ & $\mathrm{~F}$ & DEN \\
\hline CLL Pharma & $1 / 18.0$ & $2 / 15.5$ & $0 /-$ & $\mathrm{F}$ & FRA \\
\hline Merck Patent GmbH & $1 / 13.0$ & $2 / 15.0$ & $0 /-$ & $\mathrm{F}$ & DEU \\
\hline Kotobuki Pharmaceutical Co Ltd & $1 / 9.0$ & $0 /-$ & $2 / 9.0$ & $\mathrm{~F}$ & JPN \\
\hline University of Columbia & $4 / 12.5$ & $0 /-$ & $0 /-$ & $A$ & USA \\
\hline Elan Pharma International Ltd & $4 / 7.8$ & $0 /-$ & $0 /-$ & $\mathrm{F}$ & IRL \\
\hline Bayer Aktiengesellschaft & $3 / 20.7$ & $0 /-$ & $0 /-$ & $\mathrm{F}$ & DEU \\
\hline Bristol-Myers Company & $2 / 37.5$ & $0 /-$ & $0 /-$ & $\mathrm{F}$ & USA \\
\hline Ludwig Merckle K.G., Chem. Pharm. Fabrik & $2 / 34.0$ & $0 /-$ & $0 /-$ & $\mathrm{F}$ & DEU \\
\hline Yeshiva University & $2 / 12.0$ & $0 /-$ & $0 /-$ & A & USA \\
\hline Merz \& Co GmbH \& Co & $0 /-$ & $2 / 20.5$ & $0 /-$ & $\mathrm{F}$ & DEU \\
\hline $\begin{array}{l}\text { Anhui Research Center of Modern Chinese } \\
\text { Medicine }\end{array}$ & $0 /-$ & $0 /-$ & $2 / 7.5$ & $\mathrm{R}$ & $\mathrm{CHN}$ \\
\hline Chengdu Diao Pharmaceutical Group Co Ltd & $0 /-$ & $0 /-$ & $2 / 5.0$ & $\mathrm{~F}$ & $\mathrm{CHN}$ \\
\hline
\end{tabular}

Note: $F=$ Firm; $R=$ Research Institute; $A=$ Academia

Table 3: Distribution of fibrate patent by technological type at USPTO, EPO and CNIPR

\begin{tabular}{|c|c|c|c|c|c|c|c|c|c|c|c|c|}
\hline \multirow{3}{*}{ Chemical name } & \multicolumn{12}{|c|}{ Technological type } \\
\hline & \multicolumn{2}{|c|}{ Application } & \multicolumn{3}{|c|}{ Synthesis } & \multirow{2}{*}{$\begin{array}{c}\text { Purification } \\
\mathbf{U}\end{array}$} & \multicolumn{3}{|c|}{ Combination } & \multicolumn{3}{|c|}{ Preparation } \\
\hline & U & $\mathbf{E}$ & $\mathbf{U}$ & $\mathbf{E}$ & $\mathbf{C}$ & & $\mathbf{U}$ & $\mathbf{E}$ & $\mathbf{C}$ & $\mathbf{U}$ & $E$ & C \\
\hline Gemfibrozil & 4 & 0 & 2 & 0 & 3 & 0 & 2 & 0 & 0 & 7 & 4 & 1 \\
\hline Fibrates & 2 & 0 & 2 & 2 & 0 & 0 & 13 & 8 & 11 & 2 & 2 & 1 \\
\hline Fenofibrate & 1 & 0 & $\overline{0}$ & 0 & 0 & 0 & 4 & 3 & 1 & 30 & 16 & 12 \\
\hline Bezafibrate & 1 & 1 & 1 & 1 & 1 & 0 & 0 & 0 & 2 & 0 & 0 & 2 \\
\hline Ciprofibrate & 0 & 0 & 2 & 0 & 0 & 1 & 0 & 0 & 0 & 0 & 0 & 0 \\
\hline Etofibrate & 0 & 1 & 0 & 0 & 1 & 0 & 0 & 0 & 0 & 1 & 2 & 0 \\
\hline Clofibrate & 3 & 1 & 0 & 0 & 0 & 0 & 4 & 0 & 1 & 0 & $\overline{0}$ & 0 \\
\hline Etofylline clofibrate & 1 & 0 & 0 & 0 & 0 & 0 & 0 & 0 & 0 & 0 & 0 & 0 \\
\hline $\begin{array}{l}\text { Fenofibrate acid } \\
\text { choline salt }\end{array}$ & 0 & 0 & 1 & 0 & 1 & 0 & 0 & 0 & 0 & 0 & 0 & 1 \\
\hline Fibrate carboxylate & 0 & 0 & 0 & 0 & 1 & 0 & 0 & 0 & 0 & 0 & 0 & 0 \\
\hline Total & 12 & 3 & 8 & 11 & 7 & 1 & 23 & 11 & 15 & 44 & 24 & 17 \\
\hline
\end{tabular}




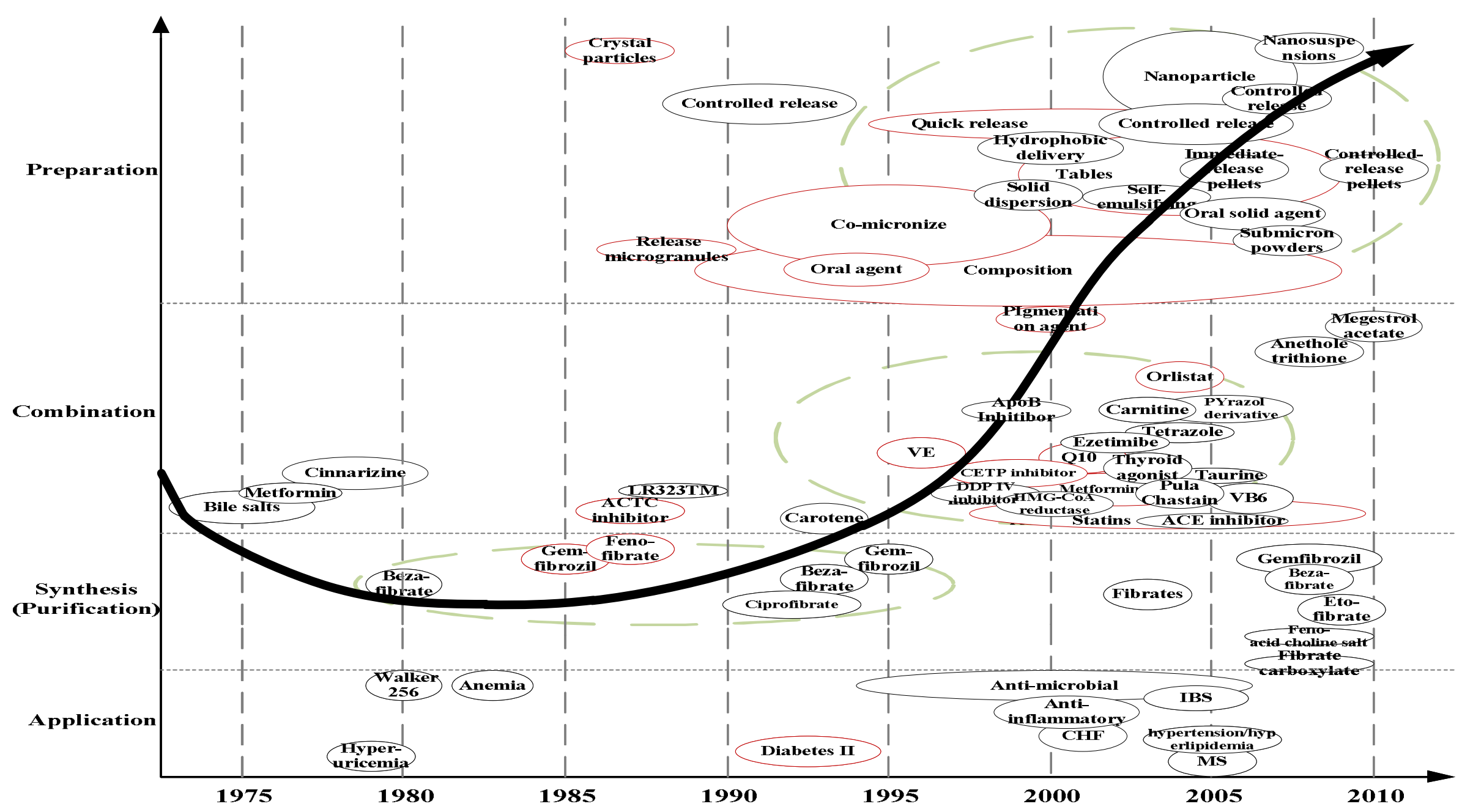

Figure 5: Technology roadmap of fibrates 
However, as the use of fenofibrate in the US increased at more than double the rate of the increase in statin use between 2002 and 2009, researchers maintained their enthusiasm for fenofibrate preparation [18]. This led to a continuous increase in the number of preparation patents. Moreover, as time went by, the fact that TG is an independent risk factor for cardiovascular disease (CVD), especially stroke, was proven by clinical trials worldwide [19-21]. These trials drew researchers' attention back to fibrates and thus led to more the appearance of new preparations with high bioavailability. Meanwhile, developing countries, realising the importance of fibrates, began to follow the fibrate pathway from the synthesis stage.

As a result, we have identified the technology trends and foci of fibrates:

- At the very beginning, researchers might first notice fibrates' effect on metabolic regulation when they were exploring combinations of other drugs. Then in the early 1970s, they first attached more importance to fibrates' combination patents with other metabolic regulatory drugs

- From the 1980s, the fibrate industry focused on basic research, i.e. the synthesis of fibrates, and on the applications of fibrates.

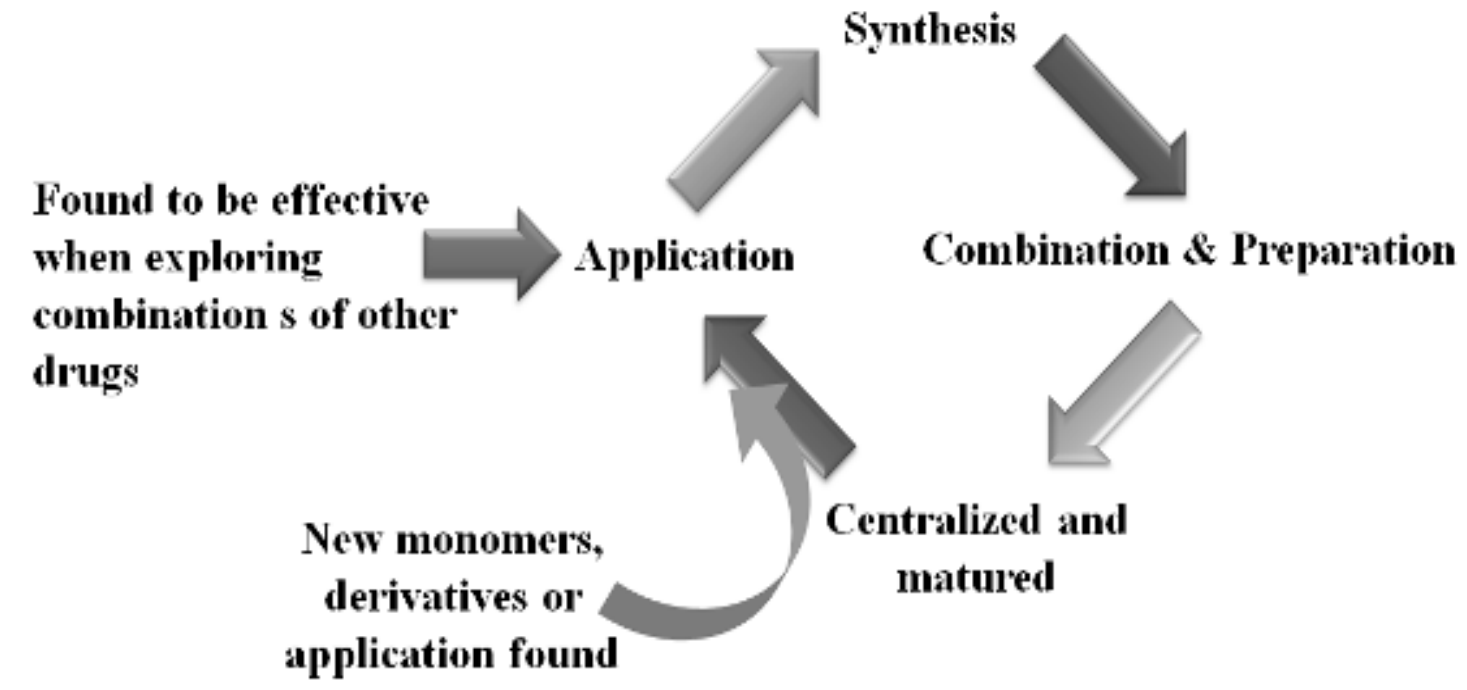

Figure 6: Evolution pathway of fibrates

In addition, the results showed that although fibrates first emerged in the US, the European Union is now the largest fibrate patent holder with the highest patents flows towards the other markets. The reasons for poor performance of China are suggested to be the following: (1) Chinese fibrate technologies are below the standard required to receive authorisation from USPTO or EPO; and (2) to apply for patents
- In around 1995, the combination of fibrates entered a stage of rapid development immediately after the development of synthesis began to slow down. Many combinations were proved to be effective in the following decade, including statins, metformin, protein inhibitors and many other chemicals.

- From 2005, the preparation of fibrates began to reach a mature stage. Other than for composition, tables or capsules, many preparations with high bioavailability appeared, such as nanoparticles and nanosuspensions.

Recently, based on the fibrate structure, new derivatives and preparation were found [22]. Novel water-soluble derivatives of fibrates were synthesised and evaluated using rats. This showed the new derivatives to have potential as potent anti-hyperlipemia drugs [23]. These new monomers and derivatives are the driving force that will lead fibrate technology evolution into a new cycle of application-synthesis-combinationpreparation (Figure 6).

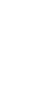




\section{CONCLUSION}

This study describes the current status and evolution pathway of fibrates. The result of our study can provide researchers, entrepreneurs, investors and policymakers with a complete picture of the development of fibrates worldwide and to assist them in their decision-making processes. By using cross-database patent review and technology roadmap, researchers can locate research foci and identify potential development directions; entrepreneurs and investors can determine orientations for new investment; and policymakers can draw an overall map of a particular developing technology and then improve on policy initiatives to guide industry.

\section{ACKNOWLEDGEMENT}

This work was supported by Research Fund of University of Macau (nos. MRG013/WYT/2013/ ICMS and MYRG160 (Y1-L2)-ICMS11-HH) and Macao Science and Technology Development Fund (no. 074/2012/A3).

\section{REFERENCES}

1. Jeppesen J, Hein HO, Suadicani $P$, Gyntelberg $F$. Triglyceride concentration and ischemic heart disease - An eight-year follow-up in the Copenhagen Male Study. Circulation 1998; 97(11): 1029-1036.

2. Amarenco $P$, Goldstein $L B$, Callahan $A$, Sillesen $H$, Hennerici MG, O'Neill BJ, Rudolph AE, Simunovic $L$, Zivin JA, Welch KMA, et al. Baseline blood pressure, low- and high-density lipoproteins, and triglycerides and the risk of vascular events in the Stroke Prevention by Aggressive Reduction in Cholesterol Levels (SPARCL) trial. Atherosclerosis 2009; 204(2): 515-520.

3. Austin MA, Hokanson JE, Edwards KL. Hypertriglyceridemia as a Cardiovascular Risk Factor. Am J Cardiol 1998; 81(4, Supplement 1):7B$12 B$.

4. Goldstein LB, Bushnell CD, Adams RJ, Appel LJ, Braun $L T$, Chaturvedi S, Creager MA, Culebras A, Eckel $R H$, Hart RG et al. Guidelines for the primary prevention of stroke: a guideline for healthcare professionals from the American Heart Association/American Stroke Association. Stroke 2011; 42(2): 517-584.

5. Zhao WH, Zhang J, You Y, Man QQ, Li H, Wang CR, Zhai $Y$, Li Y, Jin SG, Yang XG. Epidemiologic characteristics of dyslipidemia in people aged 18 years and over in China. Chin J Prev Med 2005; 39(5): 306-310.

6. Chen SH, Huang MH, Chen DZ. Identifying and visualizing technology evolution: a case study of smart grid technology. Technological Forecasting \& Social Change 2012; 79(6): 2012.

7. Hua MC, Phillips F. Technological evolution and interdependence in China's emerging biofuel industry. Technological Forecasting \& Social Change 2011; 78(7): 1130-1146.

8. Yuan JP, Yue WP, Su C, Wu Z, Ma Z, Pan YT, Ma N, Hu ZY, Shi F, Yu ZL, et al. Patent activity on water pollution and treatment in China--a scientometric perspective. Scientometrics 2010; 83(3): 639-651.

9. Noruzi A, Abdekhoda M. Mapping Iranian patents based on International Patent Classification (IPC), from 1976 to 2011. Scientometrics 2012; 93(3): 847-856.

10. Klaus B. Competitor technology intelligence in German companies. Industrial Marketing Management 1991; (20): 91-98.

11. Lamers C, Schubert-Zsilavecz M, Merk D. Therapeutic modulators of peroxisome proliferator-activated receptors (PPAR): a patent review (2008-present). Expert Opin Ther Pat 2012; 22(7): 803-841.

12. Miyachi $H$. Synthetic ligands for peroxisome proliferatoractivated receptor- $\alpha$, review of the patent literature 2000-2003. Expert Opin Ther Pat 2004; 14(5): 607618.

13. Rami HK, Smith SA. Synthetic ligands for PPARY review of patent literature 1994 - 1999. Expert Opin Ther Pat 2000; 10(5): 623-634.

14. Zheng J, Zhao ZY, Zhang $X$, Chen DZ, Huang MH, Lei $X P$, Zhang ZY, Zhao YH, Liu RS. Industry evolution and key technologies in China based on patent analysis. Scientometrics 2011; 87(1): 175-188.

15. Lacasa ID, Grupp H, Schmoch U. Tracing technological change over long periods in Germany in chemicals using patent statistics. Scientometrics 2003; 57(2): 175-195

16. Rizzo M, Berneis $K$. The clinical significance of the size of low-density-lipoproteins and the modulation of subclasses by fibrates. Curr Med Res Opin 2007; 23(5): 1103-1111.

17. The ACCORD Study Group. Effects of combination lipid therapy in type 2 diabetes mellitus. $N$ Engl J Med 2010; 362(17): 1563-1574.

18. Jackevicius CA, Tu JV, Ross JS, Ko DT, Carreon D, Krumholz HM. Use of Fibrates in the United States and Canada. JAMA 2011; 305(12): 1217-1224.

19. Freiberg JJ, Tybjaerg-Hansen A, Jensen JS, Nordestgaard BG. Nonfasting triglycerides and risk of ischemic stroke in the general population. JAMA 2008; 300(18): 2142-2152.

20. Labreuche J, Touboul PJ, Amarenco P. Plasma triglyceride levels and risk of stroke and carotid atherosclerosis: a systematic review of the epidemiological studies. Atherosclerosis 2009; 203(2): 331-345.

21. Berger JS, McGinn AP, Howard BV, Kuller L, Manson JE, Otvos J, Curb JD, Eaton CB, Kaplan RC, Lynch JK et al. Lipid and Lipoprotein Biomarkers and the Risk of 
Ischemic Stroke in Postmenopausal Women. Stroke 2012; 43(4): 958-996.

22. Shukla $P$, Srivastava $S P$, Srivastava $R$, Rawat $A K$, Srivastava AK, Pratap R. Synthesis and antidyslipidemic activity of chalcone fibrates. Bioorg Med Chem Lett 2011; 21(11): 3475-3478.
23. Nemoto $H$, Kamiya $M$, Nakamoto $A$, Matsushita $T$, Matsumura K, Hattori H, Kawamura T, Taoka C, Abe $S$, Ishizawa $K$ et al. Synthesis of highly water-soluble fibrate derivatives via BGLation. Bioorg Med Chem Lett 2012; 22(20): 6425-6428. 